Original Research

\title{
Sustainable Water Harvesting from the Atmosphere Using Solar-Powered Thermoelectric Modules
}

\author{
Caner Koc $^{1 *}$, A. Bulent Koc ${ }^{2}$, Fatih Cagatay Gok ${ }^{1}$, Hüseyin Duran³ \\ ${ }^{1}$ Department of Agricultural Machinery and Technologies Engineering, Faculty of Agriculture, Ankara University, \\ Ankara, Turkey \\ ${ }^{2}$ Department of Agricultural Sciences, Clemson University, Clemson, SC, USA \\ ${ }^{3}$ Department of Agricultural Machinery and Technologies Engineering, Faculty of Agriculture, \\ Ondokuz Mayis University, Samsun, Turkey
}

Received: 27 December 2018

Accepted: 6 March 2019

\begin{abstract}
The purpose of this study was to investigate the possibility of solar-powered thermoelectric elements (Peltier) to harvest water from the atmosphere. An Arduino-controlled model capable of harvesting water from air was designed and used in laboratory experiments. The developed prototype system was analyzed by using a package program using computational fluid dynamics. During the experiments, temperature and humidity data were recorded on a computer. We found that the Peltier used in the system developed temperature and relative humidity differences between the inlet air and outlet air from the system. These differences in temperature and humidity created an environment for harvesting water by condensing the humidity in air.
\end{abstract}

Keywords: computational fluid dynamics (CFD), Peltier, water harvesting, thermoelectric effect, solar photovoltaic energy

\section{Introduction}

Demand for fresh water has only increased with the increasing world population. However, water resources are limited due to environmental pollution [1-3]. More than $70 \%$ of the world's water resources is used for agricultural production $[4,5]$. While the water resources have stayed the same, demand for clean water was doubled during the last 20 years [6].

*e-mail: ckoc@ankara.edu.tr
Research in condensing water from the atmosphere has been increased in recent years. Sustainable and environmentally friendly water harvesting systems have been developed using renewable energy sources such as solar and wind power [7, 8]. While the efficiencies of current systems for water harvesting from the atmosphere are not high, it is expected that more efficient water harvesting systems will be seen in the future with new technologies and developments in material science.

One of the methods for harvesting water from the atmosphere is use of the thermoelectric cooling principle. Thermoelectric coolers are solid-state heat pumps and 
perform the cooling function by taking advantage of the thermoelectric (Peltier) effect, where an electric current passes across the junction of two dissimilar metals, and one of the junctions heats up while the other cools down. The Peltier effect was discovered in 1834 by Charles Athanese Peltier. It is the opposite effect of the Seebeck effect discovered in 1821 and is the principle of thermocouples. Due to developments in semiconductor technology after 1950, the Peltier effect has been used in various applications [9].

A study conducted by Jradi et al. [10] designed and optimized the performance of a thermoelectric cooling system powered with solar photovoltaic panels for freshwater production. The designed system contained a thermoelectric cooling channel, solar panels and solar distiller humidifying unit. One side of the thermoelectric cooling channel was cooled by DC-powered thermoelectric modules while the other side was insulated to generate a temperature difference between the channel surfaces to cool the air and condense water. It is reported that to produce 10 liters of water in summer in Beirut conditions, the required power consumption varied between 5.32 and $6.73 \mathrm{kWh} / \mathrm{d}$, and $45.25 \%$ savings was accomplished compared to conventional vapor compression from an atmospheric water extraction system.

Bradshaw [11] developed a system that condenses the humidity of air with thermoelectric principle. The prototype system was developed with 3D-printed materials and examined for architectural applications. The condenser was tested in 3 different seasons in 12 states in the U.S. As a result, some water is obtained, but the cost of water per liter is higher than the normal type of network water and it was concluded that this production rate can pay itself in 9 years.

Atta [12] designed and fabricated a solar-powered water condensation system using thermoelectric coolers. The developed system produced $1.0 \mathrm{liter} / \mathrm{h}$ of condensed water during the day in high humidity conditions. The same researcher reported that the installation costs of such a system was high, but it would provide cost savings in the long run with low maintenance requirements of the solar systems.

A solar-powered Peltier-based cooling system has been designed and experimented on by [12] In the study, a new approach of overlaying three thermoelectric modules was demonstrated [12]. Similar to the other thermoelectric applications, a fan and heat exchanger were used to obtain forced convection heat transfer. It was observed that the air temperature in the targeted volume of air was decreased by $9.2^{\circ} \mathrm{C}$. It was suggested that increasing the size of the heat exchanger and the capacity of the fan would increase the performance of the thermoelectric cooler [13].

In this study, a solar powered Peltier-based water harvesting prototype was developed and its performance was examined in laboratory conditions. The performance of the system was analyzed by laboratory experiments and computational fluid dynamics (CFD) in an ANSYS environment.

\section{Materials and Methods}

Water harvesting from atmospheric air is accomplished using cooling with the dehumidification process. In this process, the relatively warmer air with certain relative humidity is exposed to a surface with colder temperatures. As the warm air cools, its temperature drops and its relative humidity increases. When warm humid air gets in contact with a cold surface, its temperature drops to the dew point temperature and some of the water vapor in air condenses. Using psychrometrics charts, the properties of air during heating, cooling, humidification and dehumidification processes can be determined. For example, in a cooling process, it is assumed that the inlet air enters the cooling system at $35^{\circ} \mathrm{C}$ with $40 \%$ relative humidity, and leaves the system at $5^{\circ} \mathrm{C}$ with $80 \%$ relative humidity. From the psychrometrics chart, it is determined that the inlet air contains $14 \mathrm{~g}$ of water vapor/ $\mathrm{kg}$ of dry air and the exiting air contains $4.5 \mathrm{~g}$ of water vapor $/ \mathrm{kg}$ of dry air. Because the temperature of the exiting air is less than the wet bulb temperature of the inlet air $\left(18^{\circ} \mathrm{C}\right), 9.5 \mathrm{~g}$ of water vapor $/ \mathrm{kg}$ of dry air will condense.

A thermoelectric module (TEM) was used in this study. The TEM formed by using an equal number of $\mathrm{N}$ and $\mathrm{P}$ type semiconductors (Fig. 1). The thermoelectric coolers (TEC) are composed of several thermocouples arranged electrically in series and thermally in parallel. Electron transfers from one conductor to another cause one of them to cool down and the other one to heat. Such a thermoelectric cooling system is silent because it has no moving parts and therefore requires low maintenance. The most important feature of such a system is that it does not require any refrigerant [14].

All models and calculations in this study were based on the measurements and specifications of the TEC1-12705 thermoelectric module. TEC1-12705 is an

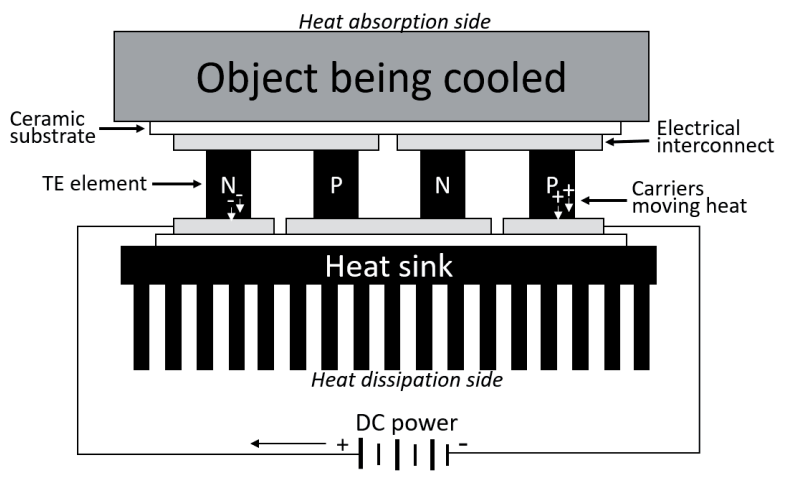

Fig. 1. A thermoelectric cooler module (https://www.testequity. com/static/155/). 


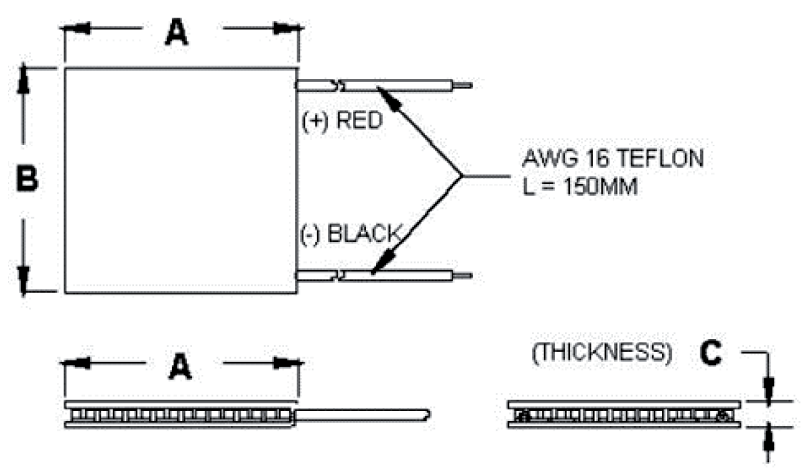

Fig. 2. Dimensions of TEC1-12705 thermoelectric module.

electronic circuit element that has been used in many industrial applications and scientific studies. This module contains aluminum oxide $\left(\mathrm{Al}_{2} \mathrm{O}_{3}\right)$ and $\mathrm{BiSn}$ as soldering material in the structure of ceramic surfaces. From the material specifications, change of current (I), resistance (R), and power (W) were examined and the operating current and voltage values were obtained. The Peltier module shown in Fig. 2 has the dimensions of $40 \mathrm{~mm}$ (A) x $40 \mathrm{~mm}$ (B) x $4 \mathrm{~mm}(\mathrm{C})$.

\section{Calculations of Condensed Water Amount of the System}

The calculations below are for air entering the system at $35^{\circ} \mathrm{C}$ and contacting the surfaces of cooling fins of the thermoelectric module and leaving the system at $5^{\circ} \mathrm{C}$. The mass flow rate of the saturated air at $35^{\circ} \mathrm{C}$ can be calculated using the following formulas [15]:

$$
\begin{aligned}
& h_{\mathrm{fg}}=2419 \times 10^{3} \mathrm{~J} / \mathrm{kg} \\
& \rho_{\mathrm{v}}=0.0397 \mathrm{~kg} / \mathrm{m}^{3} \\
& (35+5) / 2=20^{\circ} \mathrm{C}
\end{aligned}
$$

Properties of saturated air at $20^{\circ} \mathrm{C}$ film temperature were obtained from Çengel [15]:

$$
\begin{aligned}
\rho_{l} & =998.0 \mathrm{~kg} / \mathrm{m} \\
\mu_{l} & =1,002 \cdot 10^{-3} \mathrm{~kg} / \mathrm{m} \cdot \mathrm{s} \\
\mathrm{C}_{p l} & =4182 \mathrm{~J} / \mathrm{kg} \cdot{ }^{\circ} \mathrm{C} \\
k_{l} & =0.598 \mathrm{~W} / \mathrm{m} \cdot{ }^{\circ} \mathrm{C} \\
v_{l} & =\mu_{l} / \rho_{l}=1.005 \times 10^{-6} \mathrm{~m}^{2} / \mathrm{s} \\
h_{f g}^{*} & =h_{f g}+0.68 C_{p l}\left(T_{\text {sat }}-T_{s}\right) \\
& =2454 \cdot 10^{3} \mathrm{~J} / \mathrm{kg}+0.68 \cdot 4182 \mathrm{~J} / \mathrm{kg} \cdot{ }^{\circ} \mathrm{C}(35-5)^{\circ} \mathrm{C}=2539 \cdot 10^{3} \mathrm{~J} / \mathrm{kg}
\end{aligned}
$$

$$
\begin{aligned}
h & =\frac{\operatorname{Re} k_{l}}{1,08 \operatorname{Re}^{1.22}-5,2}\left(\frac{g}{v_{l}^{2}}\right)^{1 / 3} \\
& =\frac{12,37 \times\left(0,598 \mathrm{~W} / \mathrm{m} \cdot{ }^{\circ} \mathrm{C}\right)}{1,08(12,37)^{1.22}-5,2}\left(\frac{9,8 \mathrm{~m} / \mathrm{s}^{2}}{\left(1,005 \times 10^{-6} \mathrm{~m}^{2} / \mathrm{s}\right)^{2}}\right)^{1 / 3} \\
& =8759,32 \mathrm{~W} / \mathrm{m}^{2} \cdot{ }^{\circ} \mathrm{C}
\end{aligned}
$$

$$
\begin{aligned}
& A_{s}=0.0432 \mathrm{~m}^{2} \\
& \dot{Q}=h A_{s}\left(T_{\text {sat }}-T_{s}\right)=\left(8759,32 \mathrm{~W} / \mathrm{m}^{2} \cdot{ }^{\circ} \mathrm{C}\right)\left(0.0432 \mathrm{~m}^{2}\right)(35-5)^{\circ} \mathrm{C}=11352 \mathbf{W} \\
& \dot{m}=\frac{\dot{Q}}{h_{f g}^{*}}=\frac{11352 \mathrm{~J} / \mathrm{s}}{2504,3 \times 10^{3} \mathrm{~J} / \mathrm{kg}}=\mathbf{4}, 54 \times \mathbf{1 0} 0^{-3} \mathbf{~ k g} / \mathbf{s}
\end{aligned}
$$

...where:

$k$ : thermal conductivity $\left(\mathrm{W} /\left(\mathrm{m}^{\circ} \mathrm{C}\right)\right)$

$V_{\infty}$ : speed of air in the system $(\mathrm{m} / \mathrm{s})$

$v$ : kinematic viscosity $\left(\mathrm{m}^{2} / \mathrm{s}\right)$

$\mathrm{h}$ : heat transfer coefficient $\left(\mathrm{W} /\left(\mathrm{m}^{2}{ }^{\circ} \mathrm{C}\right)\right)$

$Q_{c}$ : heat energy (W)

$\mathrm{h}_{\mathrm{fg}}$ : nthalpy of evaporation $(\mathrm{kJ} / \mathrm{kg})$

$\rho_{l}:$ density of water $\left(\mathrm{kg} / \mathrm{m}^{3}\right)$

$\mu_{\text {: }}$ : dynamic viscosity of water $(\mathrm{kg} / \mathrm{ms})$

$C_{p l}$ : specific heat of water $\left(\mathrm{J} /\left(\mathrm{kg}{ }^{\circ} \mathrm{C}\right)\right)$

$k_{l}$ : thermal conductivity of water $\left(\mathrm{W} /\left(\mathrm{m}{ }^{\circ} \mathrm{C}\right)\right)$

$h_{f g}^{*}$ : latent heat of water $(\mathrm{J} / \mathrm{kg})$

m: mass flow rate of condensing air $(\mathrm{kg} / \mathrm{s})$

Pr: Prandtl number

Re: Reynolds number

\section{System Integration}

The ambient temperature of air must be reduced to the dew point temperature to condensate water vapor in air. To reduce the air temperature, a thermoelectric element (Peltier) was used. The Peltier elements can be used for two purposes as they are reversible. The upper surface of the Peltier heats up while the lower surface cools down when a current is applied. Each Peltier element has a lifetime of 220,000 h [9]. An aluminum heatsink with 12 fins of $60 \mathrm{~mm}$ x $60 \mathrm{~mm} \times 1 \mathrm{~mm}$ was used to cool the Peltier's hot surface. Two fans operating at $12 \mathrm{~V}$ (7H54A-R1) with $75 \mathrm{~mm}$ diameter propellers were used in the system. One of the fans, operating at $3200 \mathrm{RPM}$ at an air velocity of $3.02 \mathrm{~m} / \mathrm{s}$, provided a volumetric air flow rate of $132.5 \mathrm{~m}^{3} / \mathrm{h}$ into the system. Each fan required $1.56 \mathrm{~W}$ power. While one of the fans was used to cool the hot side of the Peltier element, the other one was used to force the air into system.

The major difference between the designed system in this study and the other studies is the varying crosssectional area in the system. The reduction in cross sectional area helps increasing the velocity of air while passing through the system and reduces the pressure [16]. The purpose of this is to increase the amount of air getting in contact with the cold surface. The fan is forcing the air at a speed of $3.02 \mathrm{~m} / \mathrm{s}$, but due to the change in cross-sectional area in the system, the speed of air can be up to $10.0 \mathrm{~m} / \mathrm{s}$.

SolidWorks 16 was used for the 3D design and visualization of the system. The system mainly consists of one TEC1-12705 model thermoelectric module (Peltier), two 7H54A-R1 model fans, copper body and aluminum heat exchanger, SS316 stainless steel material and high corrosion-resistant frame/body. SS316 stainless 


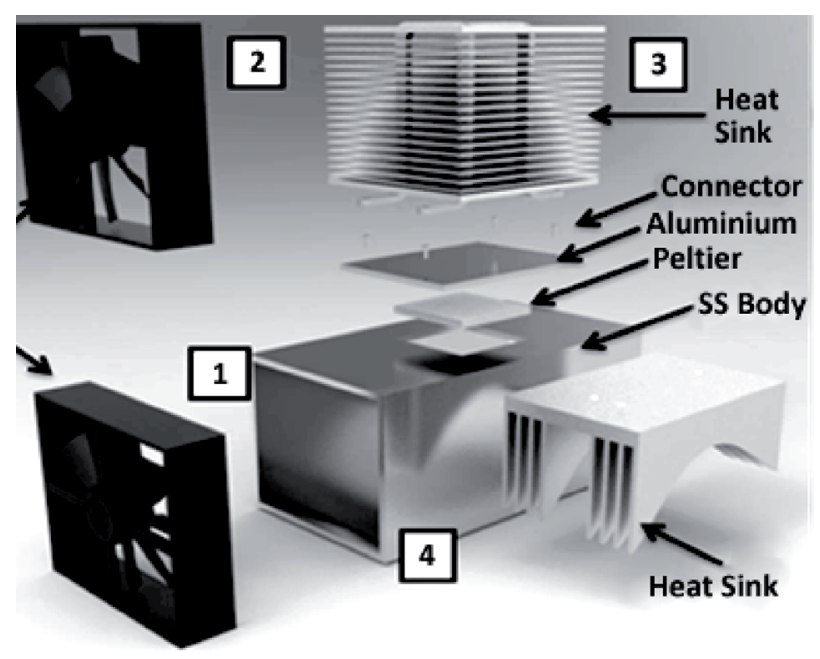

Fig. 3. Parts and assembly of the system.

steel is resistant to extreme conditions such as seawater and acidic liquids. To increase the efficiency of the condensation, two fans were used. One of the fans was used to cool down the hot surface and to dissipate the absorbed heat into the air. Fan 1 in Fig. 3 was responsible for forcing the air into the stainless-steel body and over the Peltier element. When air moving at $V_{\infty}$ velocity encounters a cold surface, it transfers some of its energy onto the cold surface and its temperature drops. The amount of heat transfer varies with $V_{\infty}$ velocity linearly.

The body is made of sheet metal having a thickness of $3 \mathrm{~mm}$ by bending. Other parts were manufactured from ASTM 6061-type aluminum with high corrosion resistance and suitable machinability using a CNC machine.

\section{Solar Panel and Circuit Board Selection}

Photovoltaic panels were used to power the fans, thermoelectric module, sensors and microcontroller. An electronic circuit was developed to store the electric energy produced from solar panels. Table 1 shows the electronic circuit elements and their power requirement.

The total electrical energy requirement of the system was approximately $28 \mathrm{~W}$. For the energy demand we selected two NES36-6-45M model solar panels, each

Table 1. Electronic components and their power requirements.

\begin{tabular}{|c|c|c|}
\hline Material & Quantity & $\begin{array}{c}\text { Power consumption } \\
\text { (W) }\end{array}$ \\
\hline Peltier & 1 & 20 \\
\hline Fan & 2 & 3 \\
\hline $\begin{array}{c}\text { Temperature and humidity } \\
\text { sensor }\end{array}$ & 4 & 5 \\
\hline Indicator & 1 & 0.03 \\
\hline
\end{tabular}

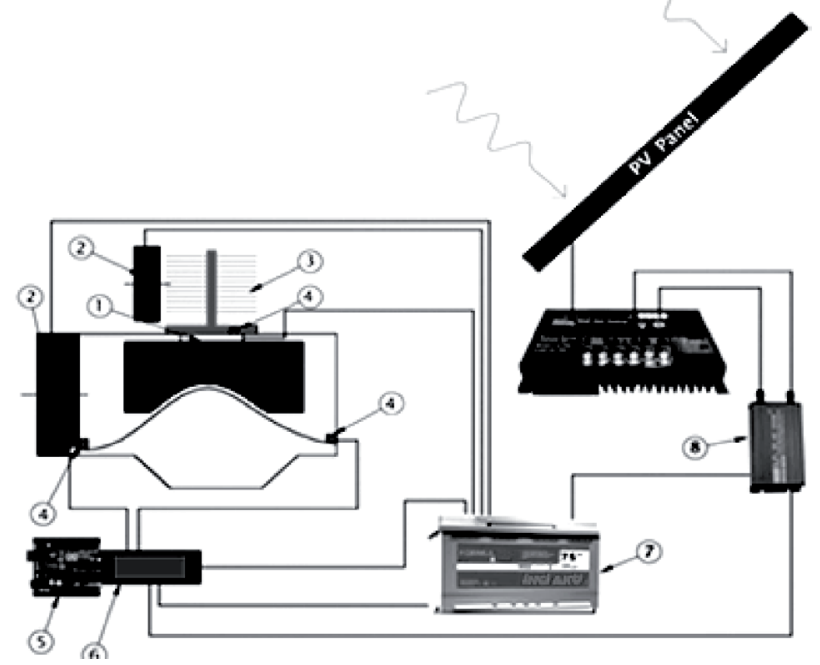

Fig. 4. Schematic representation of the system (1: Peltier element, 2: fan, 3: heatsinks, 4: DHT11 sensor, 5: microcontroller, 6: digital display, 7: 75Ah LB3 battery, 8: MEXXSUN 300W full sine inverter).

with $45 \mathrm{~W}$ maximum power. Output of the electrical energy produced by the solar panels varies with angle of sunlight during the daytime. Maximum power point tracking (MPPT) can be used to regulate the power output of the solar panels to provide a constant voltage power [17]. MPPT-type solar charging units use microcontrollers and complex algorithms to optimize the power output of the solar panels. The MPPT-type solar charging stations are $30 \%$ more efficient than other solar charging methods. In this study we selected an SR-MT 10 A MPPT solar charge controller that can work with $130 \mathrm{~W}$ solar panels with a maximum efficiency of $99.2 \%$.

For accurate operation of the system, ascendingdescending irregular power output cannot be given directly to the load. MPPT was used to regulate the power output of the solar panels [17]. At different time intervals, different power values are determined, and the process starts. These processes are performed by means of complex algorithms in the microcontroller. The MPPT-type solar charge control unit can provide an increase in efficiency of up to $30 \%$ compared to other charge control systems. To convert the DC current from the solar panel to AC current in a controlled manner, a full sinus inverter, MEXXSUN 300W, was included in the system. The inlet air and exiting air temperature and humidity were measured using two temperature and humidity sensor pairs. The SUNROM (India) DHT11 type sensors driven with Raspberry $\mathrm{Pi}$ and Arduino were used to provide the data needed with a large measuring range with high precision (Fig. 4). An Arduino Mega was used to drive the 2 fans, Peltier element and DHT 11 sensors on the system. In addition, an LCD display unit was integrated into the circuit so that the data can be displayed. A computer was used to record the measured data. 


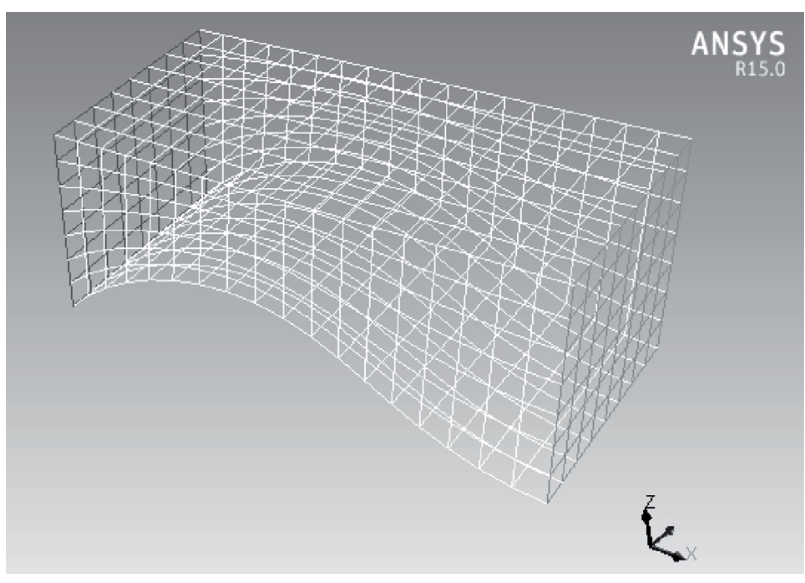

Fig. 5. Mesh structure created for the developed model.

\section{CFD Analysis}

The results and solutions of the formulations used in the design of the system, which condenses the moisture in air, are given in Formulas 1-3. Before an experimental setup was established, a package program was used to analyze the system using computational fluid dynamics. ANSYS package program was used for defining input data and specifying the environmental conditions. SolidWorks 2016 is used for solid modeling of the system. The 3D model of the system designed in SolidWorks was imported into ANSYS. The mesh structure consisting of 1.538 .612 elements was used in the interface of ANSYS (Fig. 5).

The air taken into the system was assumed to have $3 \mathrm{~m} / \mathrm{s}$ velocity and $132.5 \mathrm{~m}^{3} / \mathrm{h}$ flow rate at $30^{\circ} \mathrm{C}$ and $101,325 \mathrm{kPa}$ pressure with $40 \%$ relative humidity. The cooling fins were assumed to have a $5^{\circ} \mathrm{C}$ throughout the analysis. The analysis results showed that the relative humidity reached $100 \%$ in some parts of the fins (Fig. 6). A decrease in the temperature of the air passing through the system was also observed (Fig. 7). These results indicate that suitable environmental conditions are there to condense the water vapor in the air. Air molecules sweeping the fins cool down by dissipating some of their energy.

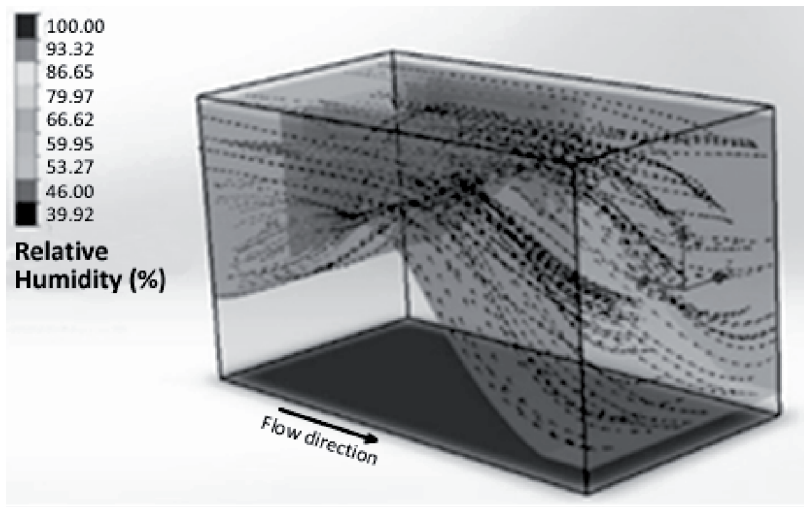

Fig. 6. Change in relative humidity.

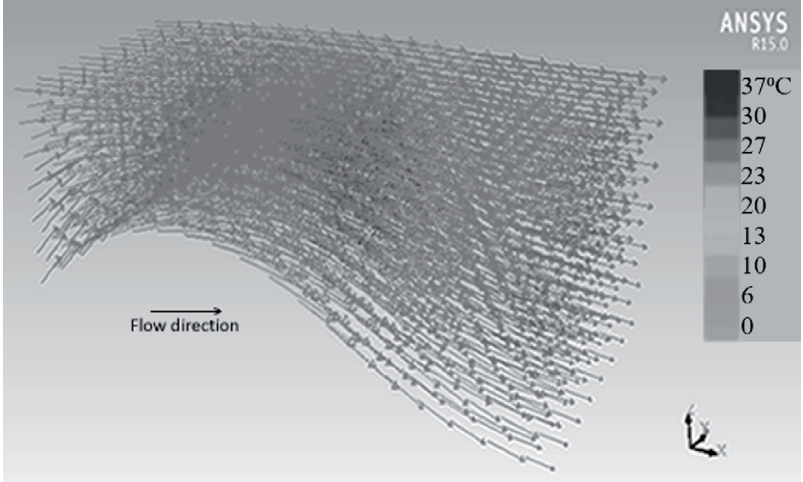

Fig. 7. Change in temperature of the air entering the system.

The regions where the highest relative humidity is formed intensively on the fins are shown in Fig. 8. Relative humidity reached the maximum concentration on the surfaces of the fins next to the cold side of the thermoelectric module. The efficiency and successful operation of the system depend on the increase in the areas shown with the shades of red color.

The change in velocity of the air in the system was also investigated. Increasing velocity and decreasing pressure in the system is a desired behavior. The radial moving air molecules at $3 \mathrm{~m} / \mathrm{s}$ with $40 \%$ relative humidity showed velocity of $8 \mathrm{~m} / \mathrm{s}$ in a narrowing section of the system (Fig. 9).

The experimental setup of the system is shown in Fig. 10. The setup was manufactured on the same scale according to the model developed in SolidWorks and ANSYS environment. The thermoelectric cooling module was operated at $12 \mathrm{~V}$ and $4.8 \mathrm{~A}$ as specified in the design, and the cooling effect was created. The system was installed so that it can operate in a closed loop. Insulating materials were used to minimize the ambient effects. The equilibrium of the system according to the laws of thermodynamics was realized by various boundary conditions and assumptions. The
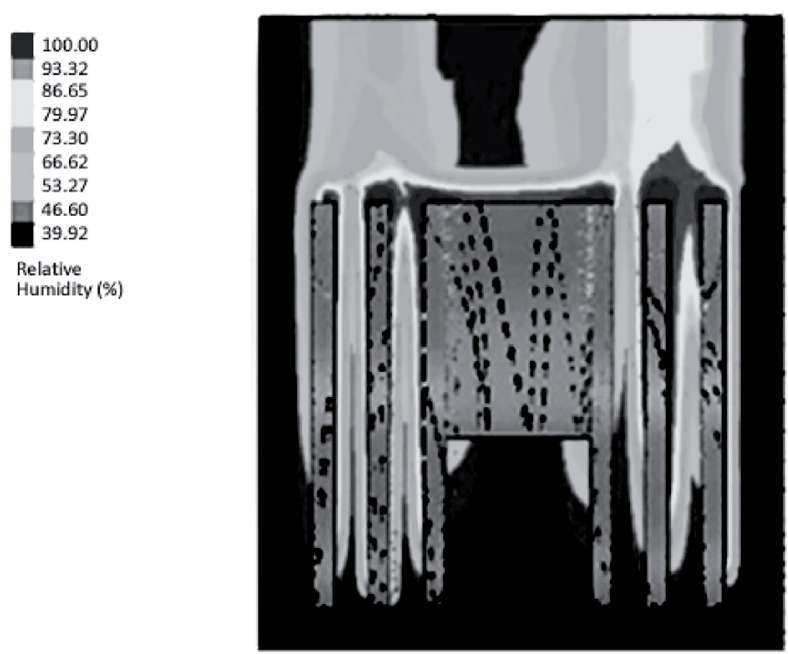

Fig. 8. Change in relative humidity in the system. 


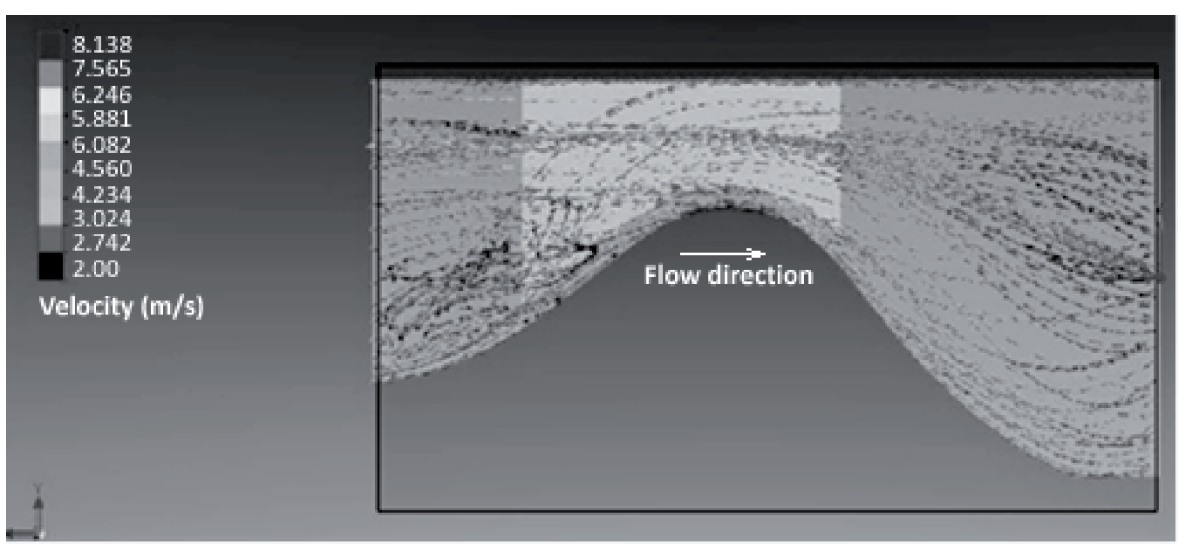

Fig. 9. Change in velocity of air in the system.

experimental set up was suitable for analyzing the changes in temperature and humidity of air at a known quantity (i.e., $1 \mathrm{~m}^{3}$ ).

In order to examine the change in the temperature and relative humidity of the air taken in the system, 5 experiments were performed at the same temperature and different humidity levels. The outside temperature and the initial temperature of the air taken in the system was $30^{\circ} \mathrm{C}$ in all experiments. Five different conditions have been created at $20 \%, 25 \%, 30 \%, 35 \%$ and $40 \%$ relative humidity levels.

In an initial boundary condition where the outdoor temperature was $30^{\circ} \mathrm{C}$ and the relative humidity was $40 \%$, the change in the relative humidity as a result of the experiments carried out in $1 \mathrm{~m}^{3}$ volume indicated that the manufactured test device was working properly (Fig. 11). We observed that the relative humidity of the air decreased by $8 \%$ in the experimental environment under the influence of the thermoelectric effect. According to the data obtained from psychometric charts, air containing $1 \mathrm{~m}^{3}$ volume at $30^{\circ} \mathrm{C}$ temperature and $40 \%$ relative humidity contains $11.2 \mathrm{~g}$ of water $/ \mathrm{kg}$ of air. The system is capable of harvesting 3.16 grams of this water vapor in the air. The system circulated the air in constant volume for about 1475 seconds, resulting in a decrease in temperature and relative humidity.

The temperature of air must be reduced to lose energy and to condense moisture in air (Fig. 12). The

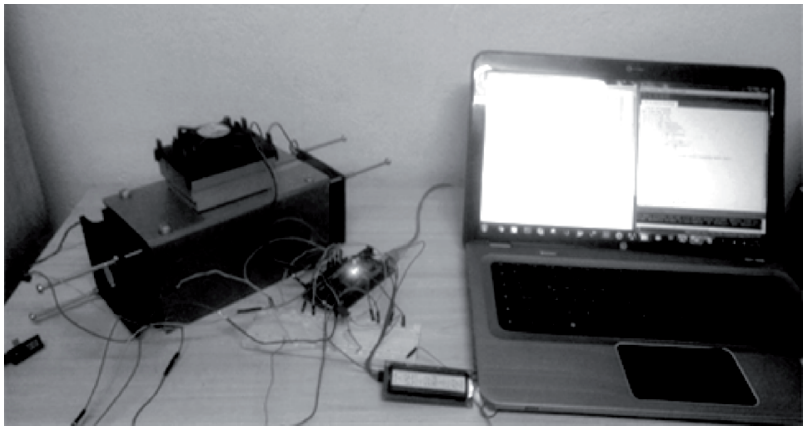

Fig. 10. View of the experimental setup. change in temperature and relative humidity values were recorded at $6 \mathrm{~s}$ intervals by means of the DHT11 sensors in the system.

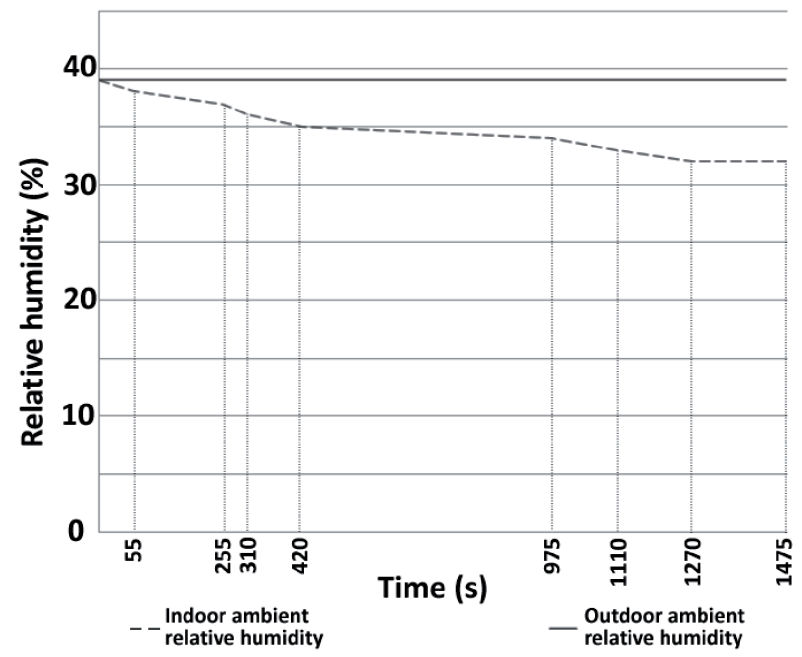

Fig. 11. Time-dependent change in relative humidity.

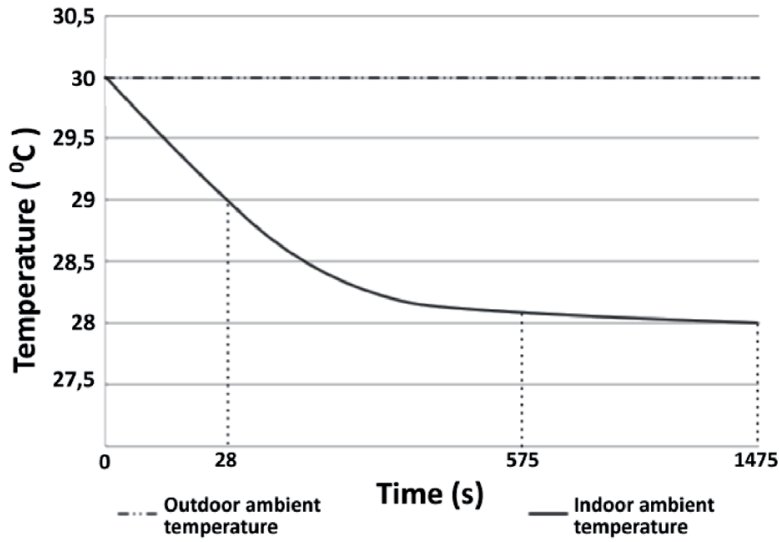

Fig. 12. Change in temperature over time. 


\section{Results and Discussion}

Analysis and theoretical calculations showed that the cooling effect occurring by the use of the thermoelectric module can be used to condense water vapor in the atmosphere. The designed system was manufactured in 1:1 scale and the changes in different weather characteristics were examined. The amount of the condensing water was determined by theoretical calculations. This amount was indirectly or directly related to many factors, including:

- Characteristics of air (relative humidity, density, dew point temperature, atmospheric pressure, altitude, etc.).

- Cooling surface characteristics (surface temperature, surface area, roughness, etc.).

- Speed and mass flow of air entering the system.

- Dew conditions.

The energy required for the system was provided from the PV panels. In the experimental study, it was observed that the relative humidity decreased from $40 \%$ to $32 \%$ in about 28 minutes. This change is an indication of the harvestability of water vapor in the air by condensation. In the calculations, it was concluded that 3.2 grams of water can be harvested from the $1 \mathrm{~m}^{3}$ volume of air [15]. However, the calculated amount of water could not be harvested due to various reasons such as the cooling power of the test device developed, the inefficiency of the thermoelectric cooling module, and the inability to create a fully isolated environment. It can be said that a significant portion of the water was condensed [18]. The higher the relative humidity value of the air in the initial conditions, the more water can be harvested. As the moisture content increases in the experimental studies performed at different humidity values, the relative humidity increase in the air was accelerated by the thermoelectric effect.

There was some condensation in the system. However, this was not on a measurable scale. By using larger surface areas and higher cooling elements, it is foreseen that the humid air contained in a fixed volume can be cooled at higher efficiency. The surface area of the cooling plate should be increased in order for the effect on the cold surface of the Peltier to come into contact with air molecules more effectively. Similar observations were made by Zhao et al. [14] and Bradshaw [11].

The method developed in this study shows that working with solar energy and accelerating the velocity of air with section narrowing are unique features of the design. Using similar dimensions of the cooling element, the amount of water obtained by Bradshaw was about $0.25 \mathrm{~L} / \mathrm{h}$. The amount of theoretical water harvested by the developed system in this study is similar to Bradshaw's, with an amount of $0.32 \mathrm{~L} / \mathrm{h}$. This level is close to similar studies $[10,11]$. In the experimental study, the amount of water that can be harvested by cooling fins and the flow rate of the fluid flow was only $0.06 \mathrm{~L} / \mathrm{h}$. In the study by Esen and Balta [19], it was stated that superimposition of multiple Peltier elements within a single body structure would increase efficiency and performance.

\section{Conclusions}

In this study, a system that can harvest water with Peltier elements by using the moisture present in the air was designed and manufactured. As a result of the experiments conducted with a finite element model, we concluded that water harvesting can be done with Peltier modules. In the system, a model that can provide energy savings by using solar panels was developed. According to the findings obtained by using such a mechanism, we concluded that the study can be transferred to practice and used in water harvesting. However, exposure to high thermal stresses and loads may shorten the economic life of Peltier elements. This can create an undesirable situation for a sustainable system. For this reason, it is predicted that the water harvesting system, which will be formed by using more than one body structure (each with a single Peltier module) can be used at low cost for many years.

\section{Conflict of Interest}

The authors declare no conflict of interest.

\section{References}

1. WEBB R., BURATINI J. Global challenges for the 21st century: the role and strategy of the agri-food sector. Animal Reproduction. 13 (3), 133, 2016.

2. LEVY D., COLEMAN W.K., VEILLEUX R.E. Adaptation of potato to water shortage: irrigation management and enhancement of tolerance to drought and salinity. American Journal of Potato Research. 90 (2), 186, 2013.

3. KAGODA P.A. Precision farming: A water management tool? Proceedings of the IASTED International Conference on Environmentally Sound Technology in Water Resources Management. 5, 2006.

4. MAHMOUDI H., SPAHIS N., GOOSEN M.F., GHAFFOUR N., DROUICHE N., OUAGUED A. Application of geothermal energy for heating and fresh water production in a brackish water greenhouse desalination unit: A case study from Algeria. Renewable and Sustainable Energy Reviews. 14 (1), 512, 2010.

5. HUSSEIN F., JANAT M., YAKOUB A. Assessment of yield and water use efficiency of drip-irrigated cotton (Gossypium hirsutum L.) as affected by deficit irrigation. Turk J Agric For. 35 (6), 611, 2011.

6. KALE S., SONMEZ B., MADENOGLU S., AVAG K., TUSRKER U., CAYCI G. Effect of irrigation regimes on carbon isotope discrimination, yield and irrigation water productivity of wheat. Turk J Agric For.; 41 (1), 50, 2017.

7. MUÑOZ-GARCÍA M.A., MOREDA G., RAGAARROYO M.P., MARÍN-GONZÁLEZ O. Water harvesting for young trees using Peltier modules powered 
by photovoltaic solar energy. Computers and electronics in agriculture. 93, 60, 2013.

8. OZBAY G., OZCIFCI A., KOKTEN E.S.. The pyrolysis characteristics of wood waste containing different types of varnishes. Turk J Agric For. 40 (5), 705, 2016.

9. LINEYKIN S., BEN-YAAKOV S. Modeling and analysis of thermoelectric modules. IEEE Transactions on Industry Applications. 43 (2), 505, 2007.

10. JRADI M., GHADDAR N., GHALI K. Optimized operation of a solar-driven thermoelectric dehumidification system for fresh water production. Journal of Energy and Power Engineering. 6 (6), 878, 2012.

11. BRADSHAW A.J. Water Harvesting Methods and the Built Environment: The Role of Architecture in Providing Water Security. 2016.

12. ATTA R.M. Solar water condensation using thermoelectric coolers. International Journal of Water Resources and Arid Environments.; 1 (2), 142, 2011.

13. BOUROUNI K., CHAIBI M.T., AL-TAEE A. Water desalination by humidification and dehumidification of air, seawater greenhouse process. Solar energy conservation and photoenergy systems, Encyclopedia of Life Support Systems EOLSS. 2011.

14. ZHAO D., TAN G. A review of thermoelectric cooling: materials, modeling and applications. Applied Thermal Engineering. 66 (1-2), 15, 2014.

15. CENGEL Y. Heat and Mass Transfer: A Practical Approach, sl. McGraw-Hill; 2006.

16. FAULKNER B.E., YTREBERG F.M. Understanding Bernoulli's principle through simulations. American Journal of Physics. 79 (2), 214, 2011.

17. HIWALE S., PATIL M.V., VINCHURKAR H. An Efficient MPPT Solar Charge Controller. International Journal of Advanced Research in Electrical, Electronics and Instrumentation Engineering (An ISO 3297: 2007 Certified Organization). 3 (7), 2014.

18. CHATTERJEE S., PANDEY K. Thermoelectric coldchain chests for storing/transporting vaccines in remote regions. Applied energy. 76 (4), 415, 2003.

19. ESEN D.Ö., BALTA E. The Performance Analysis of Solar Powered Thermoelectric Cooling System. 134, 31, 2013 [In Turkish]. 